\title{
PORTER'S ANALYSIS AS A STANDARDIZED PROCESS APPLICABLE IN INDUSTRIAL COMPANIES
}

\begin{abstract}
Reliability and safety of energy, drinking water deliveries and draining wastewater from built- up areas in cities and villages have many proportions and technical-operational conditions. Among basic requirements of the use of all types of residential or manufacturing objects in the $21^{\text {st }}$ century is reliable delivery of drinking water, draining and cleaning of urban and industrial sewage. Disturbance or putting out of service of this type of infrastructure has always a domino effect. Gradually growing reliance of user base of all types of drinking water consumers leads especially in the section of the public or private infrastructure to restriction or complete stoppage of their operation. The following article defines in basic range the ways and means how to lower the danger that an emergency situation in operational systems of drinking water will be unmanageable and how to prevent natural or anthropogenic threats at the particular type of technical infrastructure.
\end{abstract}

Keywords: Water, drinking water, water main, hydraulic surrounding, infrastructure of an area, risk, risk analysis.

\section{Introduction}

The business environment, especially in recent years, has been influenced by frequent and sudden changes as well as by strong competition. Early prediction of market opportunities, identifying threats and, of course, solving potential problems of strategic nature result in business success [1]. Therefore, the strategic analyses that can draw attention to potential opportunities and threats should be an integral part of the business activities of each economic entity. This is especially true for industrial companies, as demand for their products is by the definition of $\mathrm{B} 2 \mathrm{~B}$ market a derived demand. It is true that the ideal model of strategic management of the company does not exist; however, some similarities in taking certain linked steps can be traced as shown in Fig. 1, where the strategy life cycle is illustrated. It would be a mistake to try using universal strategies in all the companies.

Properly formed strategy must be tailor-made for each company, especially on B2B market, where there are fewer, but larger companies than on the consumer market. And an important starting point for formulating strategy is the result of strategic analysis. The aim is to identify and evaluate all relevant factors which may be presumed to influence the final choice of company's targets and strategy.

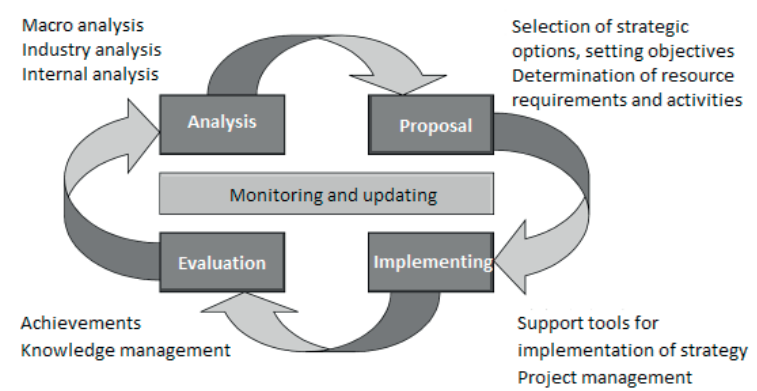

Fig. 1 Life cycle of a strategy [2]

The competition has a substantial influence on the achievement of specific objectives on the B2B market. An important method of the strategic analysis is the analysis of competitive forces. The most known is the Porter five forces analysis that identifies the degree of influence affecting the given industry or company. The goal of the model is to identify and understand the forces that take effect within the industry. Enterprise that wants to be successful should respond to these forces and deal with them and, if possible, change their influence to their advantage [ 3 and 4 ].

\footnotetext{
* ${ }^{1}$ Roman Kozel, ${ }^{2}$ Milan Mikolas, ${ }^{1}$ Sarka Vilamova, ${ }^{1}$ Katerina Chuchrova, ${ }^{3}$ Marian Piecha

${ }^{1}$ Institute of Economics and Control Systems, Faculty of Mining and Geology, VSB - Technical University of Ostrava, Czech Republic ${ }^{2}$ Institute of Mining Engineering and Safety, Faculty of Mining and Geology, VSB - Technical University of Ostrava, Czech Republic ${ }^{3}$ Section of Support for Small and Medium-sized Enterprises, Ministry of Industry and Trade of the Czech Republic E-mail: roman.kozel@vsb.cz
} 


\section{Analysis}

There are no exact instructions for implementation of the Porter's analysis even though it is one of the most used analyses. This method is very often used for e.g. situational analysis or to set the competitive advantage, but its procedure and results are merely subjective, verbal interpretation of an expert applicable only to a problem which is currently being solved.

The aim of the research team is to create its standardized, visualized version bearing specific results suitable for presentation to the TOP management. The tendency is to create a user-friendly software environment so that the managers of the industrial companies, who are not usually involved in this matter, are able to create such analysis themselves.

Many authors pursued the topic of Porter's analysis in their published works. This analysis was, for instance, used in an article dealing with aspects of maritime safety, such as control of the sea, nuclear deterrence and defence against ballistic missiles, as well as naval consensus. [5] The analysis was also used when examining the competitive advantage of the Jordan Phosphate Mines Company (JPMC) based in Jordan and founded in 1949 [6] and in other articles following the force of the competition in the given industry [7].

Porter five forces analysis is also used when formulating the marketing strategy as it was, for example, used in the articles Developing Marketing Strategy for Electronic Business by Using McCarthy's Four Marketing Mix Model and Porter's Five Competitive Forces [8] and Designing marketing strategy using the five competitive forces model by Michael E. Porter - case of small bakery in Croatia [9].

The resulting data were visualized in this research and research data for the evaluation was collected on the basis of a questionnaire that was based on similar issues, which are defined in the model that is currently being constructed by the authors of this paper. Other articles deal primarily with innovation, modernization and improvement of Porter's ideas in relation to the new trends and facts in marketing and strategic areas [10 and 11]. The theoretical basis and application of Porter's analysis that were used in those articles will serve as groundwork for standardization of Porter's analysis with the use of suitable graphic outcomes.

\section{Methods and Procedures}

The aim of the research is to create a user-friendly software environment that offers processing of selected analyses, thus standardized inputs, built-in algorithms and methods of computation and subsequent standardized outputs in the form of tables and graphic outcomes. The system is therefore formed by the combination of Excel spreadsheets and VISUAL BASIC programming background to create the utility program.
Functionality of the standardized Porter's analysis in this software environment was tested by the means of competitive analysis implementation in this support system on real data of a company that is involved in the field of mining and processing of stones in the Moravian-Silesian Region. Due to the fact that data used in this article are real data and, therefore, are subject to secrecy, the mining company will be addressed as $\mathrm{ABC}$ and its suppliers / customers as companies Alpha, Beta, Gama, Delta and Omega.

As inputs for the system analysis the secondary data from internal company documents, data from previous analyses of the market and specific information and professional judgments of their managers were mostly used.

An important characteristic of the industry are competing forces influencing that sector. Analysis usually includes five Porter's forces, but it depends merely on the evaluator which of the forces affecting the company will be chosen. The menu of Porter's analysis guides the evaluator on how to proceed with individual analysis, see Fig. 2. For every force a main table, which includes a number of statements that express the level of dependence on the given group influencing the company, is defined.

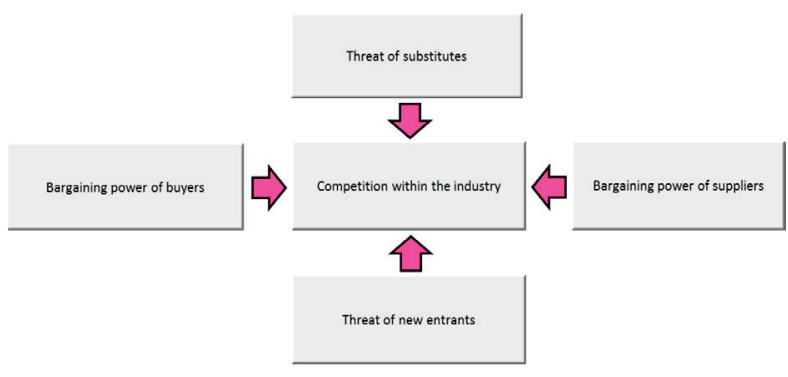

Fig. 2 Porter's analysis menu

The evaluators express the degree of compliance with individual claims on the scale of 0 - 10 ( 0 - absolutely disagree, 10 - agree completely), which also illustrates the strength of influence ( 0 - no influence, 10 - great influence). The values indicating the score of influence of individual factors are calculated by the use of an arithmetic average and the influence coefficient is derived for every analyzed group of factors:

- $\quad\langle 0$; 3.50 $>$ negotiating strength of the group is small

$<3.51 ; 7.00\rangle$ negotiating strength of the group is average

$<7.01 ; 10.00\rangle$ negotiating strength of the group is great.

When testing the functionality of the software support for standardization the Porter's analysis, all five forces (groups) were tested, and for each of the force at least 7 factors that were further evaluated had been set.

Analysis of the bargaining power of buyers - this partial analysis shows the influence of the buyers, customers. The question is what the power of our customers is. Strong customers may cause the loss of potential profit; they may negotiate many 


\begin{tabular}{|c|c|c|c|}
\hline \multicolumn{4}{|c|}{ CUSTOMERS OF THE COMPANY } \\
\hline \multirow{2}{*}{ No. } & Statement & $\begin{array}{c}\text { Weight } \\
\text { of statement }\end{array}$ & Customers \\
\hline & Use pair comparison & $\nabla$ & \\
\hline 1 & We do not have enough customers & $21 \%$ & 7 \\
\hline 2 & Customers buy large volumes & $21 \%$ & 5 \\
\hline 3 & The industry has a large number of enterprises & $21 \%$ & 8 \\
\hline 4 & Our product is very standardized & $9 \%$ & 10 \\
\hline 5 & Customer purchases represent a large percentage of total sales in the industry & $9 \%$ & 2 \\
\hline 6 & Risk of integration of buyers & $4 \%$ & 1 \\
\hline 7 & The purchased product is an important input or necessary product. & $7 \%$ & 3 \\
\hline 8 & $\begin{array}{l}\text { For the buyer it is economically more advantageous to purchase inputs } \\
\text { from several suppliers. }\end{array}$ & $7 \%$ & 8 \\
\hline 9 & & $0 \%$ & \\
\hline \multirow[t]{3}{*}{10} & & $0 \%$ & \\
\hline & Average rating & $100 \%$ & 6.18 \\
\hline & Total sales & CZK & \\
\hline
\end{tabular}

Fig. 3 Analysis of the customers

privileges and so on. Basic evaluating questions used when testing the system are stated in the table shown in Fig. 3.

Competition within the industry - Due to the limited number of customers on the B2B market, the intensity of this competitive force represents a noteworthy signal which predicates how much power the competing companies place into the efforts to gain a better market position.

When testing real data for this area the following statements were chosen: Is there a large number of direct competitors in our industry? Is it a capital-intensive industry? Are there large differences in quality among the competitors? Are there large differences in price among the competitors? The competition offers better accompanying services. High fixed costs. Manufactured/offered product/service is poorly differentiated. High barriers to exit the industry. Slow growth of the industry / Slow demand growth.

\section{Threats of substitutes}

Companies operating within one industry are in direct competition with companies in different industry if their products represent a good substitute. Competitive threats were during the testing learned by the use of the following factors: The price of a substitute lower than the price of our product/service. The quality of the substitute is better than of our product/service. The substitute offers better accompanying services. Better shelf life of the product. Better handling of the substitute. Better recyclability of the substitute. Quicker delivery of the substitute. More favorable features of the substitute. The cost of the customer to switch to substitute is negligible [12].

\section{Analysis of the threat of new entrants}

Low barriers to enter the industry could represent a significant threat of new entrants to the industry. That is why during the testing the following entry barriers were formulated: Do you have any special technologies and know-how? There are too many legislative measures and frequent interference of the state. Your company has high demands regarding the human resource. The experience plays an important role within your industry. You are effective in achieving large volumes. You have dedicated customers. Your brand is well-known. The market penetration into your industry sector is investment demanding. You possess cost advantages. You possess distribution channels.

\section{Analysis of the bargaining power of suppliers}

The power can be very low and the suppliers therefore have no impact on our business. Or their power can be so high that any interference from their side can have a great influence on our production. The evaluation theses could be, for instance, defined in the following way: The supplier is hard to replace. There are not enough suppliers on the market. There is no substitute. The supplier is threating by possible integration. Supplier's product is an important entry for the business of the customer. The industry is not a primary aim of the supplier. What are the overall annual costs of the supplier?

Figure 3 shows that pre-defined statements do not have to have the same influence for particular industry or company. Therefore, the possibility to set the weight of importance of individual evaluation criteria within the complex evaluation must exist in the way that the more importance the criterion has the more weight it has. In the basic design of the tested system are 


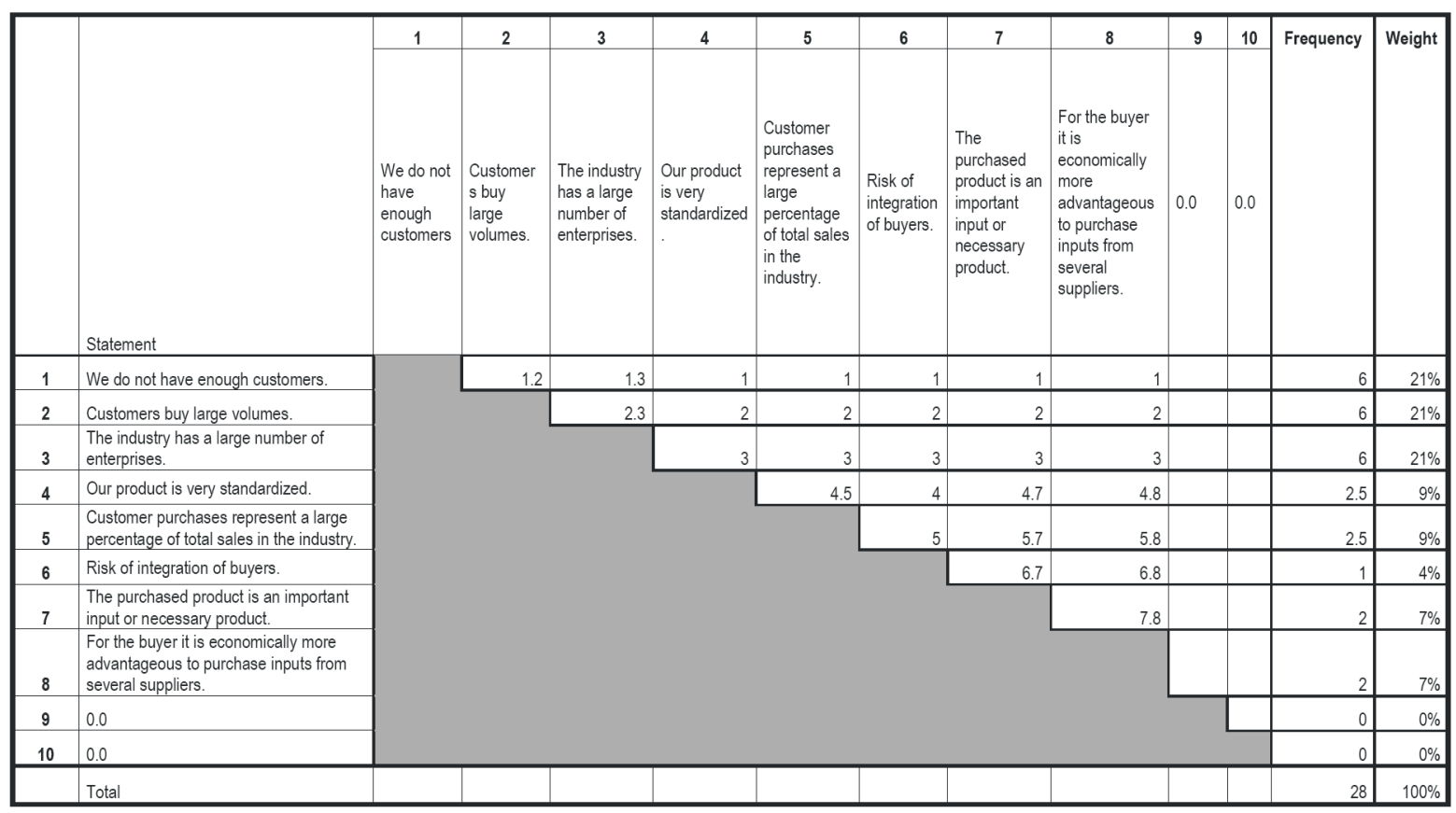

Fig. 4 Table of pair comparison analysis of the customers

all statements of the same significance. When using the "use pair comparison" (see Fig. 3), it is possible to define the importance of individual statements and thereby determine their weight. The method of pair comparison was used to set the importance/weight during the testing phase. This method determines the preferential relationship between a pair of criteria. The purpose is to outline the number of preferences for each criterion in relation to all the other criteria of the given file (see diagram of Fig. 4).

In the upper right part of the table (upper triangular matrix) the evaluator examines whether the pair of criteria prefers the criteria stated in a line before the criterion set out in a column. If that is the case, the evaluator writes the number of criterion stated in the line into an appropriate field, if it be to the contrary, the evaluator writes the number stated in the column. If the evaluator perceives the criteria equally important, both criteria numbers must be written. Resulting weight of the criteria for each criterion stated in \% is derived as a number of its preferences that is also equal to the sum of preferences in the line and column of that criterion. The result of each analysis is partly the strength of influence of individual groups on the company and partly the average evaluation of the group. After completing all the relevant groups influencing the course of events in the company, the final result of the influence can be seen on the spider diagram that describes the tested company with regard to the strength of the influencing powers. The number of angles depends on the number of selected influencing powers.

\section{Results}

The authors of this article filled in the programmed Porter's analysis together with the managers of company $\mathrm{ABC}$. Due to the limited maximum number of pages of this article, the authors will only present the results of the implementation and outcomes of the suppliers analysis. At first it was necessary to appoint a supplier of company ABC. For the purpose of this analysis five different suppliers were selected. The preferences of individual statements were set by the means of pair comparison. The weight of the statement will consequently appear in the third column of the table in Fig. 5.

After completing the suppliers evaluation, the value of "Average evaluation" of a specific value of the average evaluation of individual suppliers, can be seen in the penultimate line. The last column states the average of the whole group. In this case the influence coefficient equals 7 , which means that the negotiating power of this group is great.

In the last line "The total cost" the evaluator must state the annual costs associated with using the services of a particular supplier. As soon as all the required parameters were entered, it was possible to choose from the graphical tools menu and display the results of the analysis. As an example we can show, e.g., a chart evaluation of individual suppliers or a portfolio chart, the average rating of the supplier / costs of supplier. It depends purely on the requests, needs and choice of the evaluator.

In this article the chart showing the average evaluation of suppliers is shown in Fig. 6. This chart shows the rate of influence individual suppliers have on the company in question, 


\begin{tabular}{|c|c|c|c|c|c|c|c|c|c|c|c|c|c|}
\hline \multicolumn{14}{|c|}{ THE LARGEST SUPPLIERS } \\
\hline \multirow{2}{*}{ No. } & Statement & $\begin{array}{l}\text { Weight of } \\
\text { statement }\end{array}$ & 1. & 2. & 3. & 4. & 5. & 6. & 7. & 8. & 9. & 10. & \multirow{2}{*}{$\begin{array}{c}\text { Average } \\
\emptyset\end{array}$} \\
\hline & Use pair comparison & $\square$ & Alpha & Beta & Gamma & Delta & Omega & & & & & & \\
\hline 1 & Supplier is hard to replace. & $33 \%$ & 10 & 6 & 6 & 1 & 6 & & & & & & \\
\hline 2 & There are only few suppliers. & $27 \%$ & 10 & 7 & 8 & 2 & 7 & & & & & & \\
\hline 3 & There is no substitute. & $13 \%$ & 10 & 10 & 7 & 10 & 9 & & & & & & \\
\hline 4 & Supplier is threating by possible integration. & $10 \%$ & 6 & 6 & 7 & 1 & 1 & & & & & & \\
\hline 5 & $\begin{array}{l}\text { Supplier's product is an important input for the } \\
\text { business of a customer. }\end{array}$ & $13 \%$ & 10 & 10 & 10 & 10 & 9 & & & & & & \\
\hline 6 & $\begin{array}{l}\text { The industry is not an important customer of the } \\
\text { supplier. }\end{array}$ & $3 \%$ & 10 & 8 & 10 & 10 & 3 & & & & & & \\
\hline 7 & & $0 \%$ & & & & & & & & & & & \\
\hline 8 & & $0 \%$ & & & & & & & & & & & \\
\hline 9 & & $0 \%$ & & & & & & & & & & & \\
\hline \multirow[t]{3}{*}{10} & & $0 \%$ & & & & & & & & & & & \\
\hline & Average rating & $100 \%$ & 9.60 & 7.40 & 7.43 & 3.97 & 6.47 & 0.00 & 0.00 & 0.00 & 0.00 & 0.00 & 7 \\
\hline & Total costs & CZK & 1170000 & 260000 & 2400000 & 10680000 & 6000000 & & & & & & 4102000 \\
\hline
\end{tabular}

Fig. 5 The analysis of suppliers

therefore, to what extent they are able to influence the business of the analyzed company. On top of that, each supplier has a different size of bubble on the 3D chart, showing the size of the supplier in terms of annual costs. The chart is designed so that those suppliers who occur in the upper third of the chart have the greatest influence on the analyzed company. The results obtained from company $\mathrm{ABC}$ imply that the greatest influence is shown by the supplier called Alpha that supplies the main raw material. The company has concluded a number of long-term contracts with this supplier until the year 2023 for excavation of spoils. Among other companies that have a great influence on the above mentioned company are also suppliers Beta and Gamma. The charts also clearly show that all the other analyzed suppliers are those with an average bargaining power. Overall, the smallest impact on the business of company ABC has supplier Delta, despite the fact that the annual costs spend on these suppliers are by far the greatest (see the biggest bubble).
Analyses of the remaining four forces of Porters analysis were carried out analogically as the partial competitive forces are programmed in a similar way as the bargaining power of suppliers. However, each of the forces has its own specifics. For instance, with the analysis of bargaining power of buyers, it is not necessary to name individual customers if the evaluator does not wish to do so, it is sufficient to evaluate them as a whole. The outcomes of the entire Porter's analysis in the tested system are a table and a chart "Average evaluation of competitive forces". It is, therefore, possible to create a model of competitive forces and determine the degree of rivalry between the individual parts, see Fig. 7.

The reference chart in the picture displays the result of system testing on real data, show the most significant risks and threats and at the same time opportunities for development of the company that can help to achieve either current or future goals. The biggest threat to company $\mathrm{ABC}$ represents the competition within the industry.

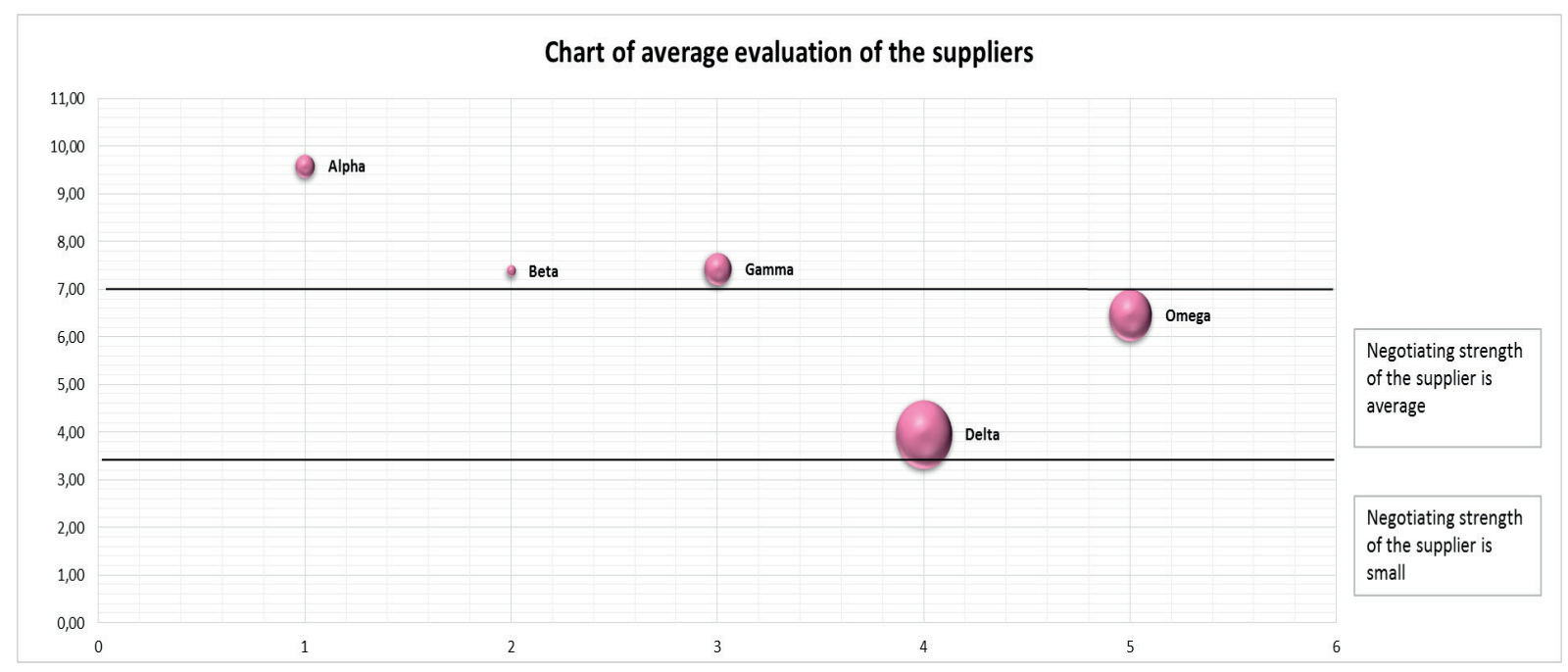

Fig. 6 Average evaluation of suppliers 


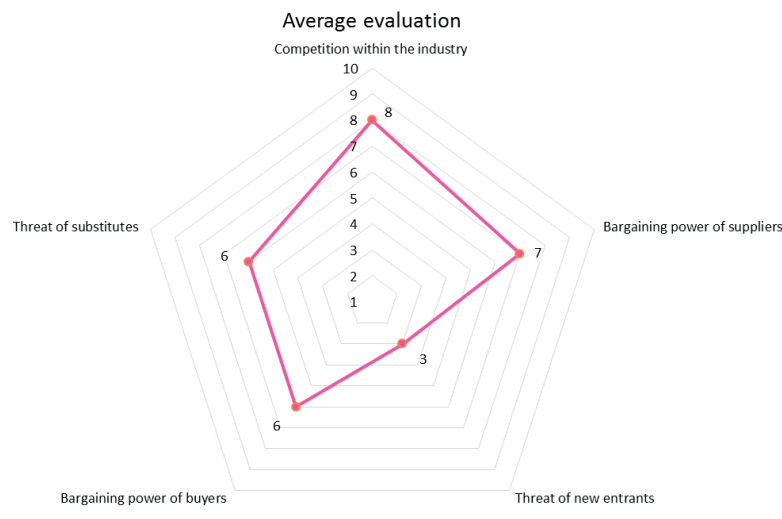

Fig. 7 Final evaluation

The company should, therefore, focus on their products and decide how to surpass its competitors and how to differentiate. Simultaneously it was found that other groups of competitive forces reach rather high or medium influence which alerts the managers to start focusing at these points as well.

The good news is that there is only a small threat of new entrants which is demonstrated by a very low influence coefficient. The cause may be high investment to enter the business in this field, announced regulations, etc.

\section{Conclusion}

\section{References}

[1] KOZEL, R., L., MYNAROVA, SVOBODOVA, H.: Modern Methods and Techniques of Marketing Research (in Czech). Praha : Grada, 2011. 304 s. ISBN 978-80-247-3527-6.

[2] SEDLACKOVA, H., BUCHTA. K.: Strategic Analysis - $2^{\text {nd }}$ ed. revised and supplemented (in Czech), Praha : C. H. Beck, 2006,121 p., ISBN 80-717-9367-1.

[3] JAKUBIKOVA, D.: Strategic Marketing: Strategy and Trends. Praha : Grada, 2008, 269 p., ISBN 978-80-247-2690-8.

[4] MALlYA, T.: Principles of Strategic Management and Decision Making (in Czech). Praha : Grada, 2007, 246 p., ISBN 978-80-2471911-5.

[5] YETKIN, U.: Revealing the Change in the Maritime Security Environment through Porter's Five Forces Analysis. Defence Studies. 2013, vol. 13, 4, pp., 458-484. ISSN 1470-2436.

[6] ALRAWASHDEH, R.: The Competitiveness of Jordan Phosphate Mines Company (JPMC) Using Porter Five Forces Analysis. Intern. J. of Economics and Finance. 2013, vol. 5, No. 1, pp. 191-200. ISSN 1916-971X.

[7] RICE, J. F.: Adaptation of Porter's Five Forces Model to Risk Management. Defense AR J., 2010, vol. 17, No. 3, pp. 375-388. ISSN 1553-6408.

[8] AZADI, S., RAHIMZADEH, E.: Developing Marketing Strategy for Electronic Business by Using McCarthy‘s Four Marketing Mix Model and Porter's Five Competitive Forces. EMAJ: Emerging Markets J., 2012, vol. 2, No. 2, pp., 46-58. ISSN 2159-242X.

[9] RENKO, N., SUSTIC, I. BUTIGAN, R.: Designing Marketing Strategy Using the Five Competitive Forces Model by M. E. Porter - Case of Small Bakery in Croatia. Intern. J. of Management Cases. 2011, vol. 13, No. 3, pp. 376-385. ISSN 1741-6264.

[10] GRUNDY, T.: Rethinking and Reinventing Michael Porter‘s Five Forces Model. Strategic Change. 2006, vol. 15, No. 5, pp. $213-229$. Online ISSN: 1099-1697.

[11] HANZELKOVA, A. et al.: Business Strategy: Step by Step (in Czech). Praha : C. H. Beck, 2013, 159 p., ISBN 978-80-7400-455-1.

[12] MIKLOSIK, A.: Selected Aspects of Systemic Approach to Project Management. Actual Problems of Economics: Scientific Economic J., 2014, No. 5, pp. 195-202. ISSN 1993-6788. 